\title{
Experimental Investigation and Performance Analysis of Ceramic Inserts in Laser Assisted Turning of Waspaloy
}

\author{
Martyna Wiciak ${ }^{1, a}$, Tadeusz Chwalczuk ${ }^{1}$ and Agata Felusiak ${ }^{1}$ \\ ${ }^{1}$ Poznan University of Technology, Piotrowo 3 St., 60-965 Poznan, Poland
}

\begin{abstract}
In this paper, the influence of laser assisted turning of hard-to-cut nickel-based superalloy on tool cutting ability was presented. The conducted research involved the machining performance along with tool life of ceramic inserts during turning of heat-resistant alloy under a trade name Waspaloy. The ceramic insert with geometry in accordance with the ISO - RPGX 120700 T01020 were applied during longitudinal turning with laser beam. The investigations has been completed with various cutting conditions such as laser power $P$, cutting speed $v c$, feed $f$ and depth of cut $a_{p}$. In order to determine the relations between the tool wear and cutting time, the tool life $T$ has been selected. The increment of tool wear was correlated with the change of vibration signals and the critic points of tool wear was presented. In addition, the shape and form of chip was evaluated based on macroscopic observation and SEM analyses. The conducted research was primarily focused on effective application of ceramic inserts during turning Waspaloy with laser beam and comparison this technology with conventional machining.
\end{abstract}

\section{Introduction}

Mechanical processing of hard-to-cut materials, ex. superalloys and aluminum-ceramic composites is a challenge for cutting tools $[1,2]$. An important aspect is a replacement of the tool at an appropriate moment, before the catastrophic tool wear. In parallel, the process is aimed to maximal utilization of cutting tools and thereby obtaining longer tool life. The right selection of tool material and insert's geometry allows to achieve required dimensional and shape precision. Moreover, it may lead to improve machining conditions and maximize the tool life $[3,4,5]$.

Cutting inserts' wear is related with different mechanisms which accompany machining processes, ex. abrasion and adhesion. In case of machining hard-to-cut materials such as heat-resistant alloys, most of research suggest that abrasive wear is the most evident and it results from hard phases occurring in microstructure of superalloys [6]. In paper [1] the influence of two hard-to-cut materials microstructures: Waspaloy and Inconel 718, on the wear of cutting inserts [7] was investigated. It was presented that high temperatures occurring in cutting zone have the main impact on precipitated wear. On the other hand, in paper [5] wear of polycrystalline diamond (PCD) tools during machining of chromium carbide semi-finished product was investigated. Researches focus as well on carbides milling [8] and examination of surface machined using $\mathrm{CBN}$ cutting edges [9]. Basing on the

\footnotetext{
${ }^{\mathrm{a}}$ Corresponding author : martyna.r.wiciak@doctorate.put.poznan.pl
} 
researches it was concluded that the material is hard-to-cut and application of methods which improve efficiency of machining is recommended. To improve machining conditions and to decrease tool wear new methods of cooling (ex. cryogenic cooling) or special methods which assist machining are applied [10]. One of the popular technologies is laser assisted machining which enables effective forming of superalloys $[11,12,13]$. Due to located heating and softening of material which resulted in reduction of its durability in cutting zone, lower cutting forces and wear of cutting tools with simultaneously improve of machined surface quality were obtained. $[2,14]$ Researches in which laser assist was applied to improve machining conditions present that proper selection of parameters, like laser beam power, cutting speed and feed rate, have influence on temperature in the cutting zone [14].

In paper [14] the comparison of cutting inserts' durability during conventional turning and laser assisted turning was presented. 50\% increase in inserts' durability during machining of Waspaloy was found due to applying the laser assist. Moreover, decrease of cutting forces by $20 \%$ was spotted. Increasing amount of researches focus on analysis of vibrations which accompany the machining process [15]. Generating of too heavy vibrations may lead to a loss of process stability. Various technologies are applied to reduce values of vibrations' accelerations. In paper [16] the decrease in amplitude of vibrations during laser assisted turning of cemented carbides was spotted. For examination of hard-to-cut materials machinability the analysis of chip morphology is being carried out $[17,18]$. It is commonly known that the shape of chip is influenced by machining conditions, tool's geometry, machined material and the type of coolant. Appropriate forming and flow of chip is significant for machining process, thus selection of proper cutting parameters eliminates generating short and thick chips and decrease cutting forces and mechanical vibrations. In paper [19] conventional machining was compared with LAM during turning of Inconel 718. It was found that besides reduction of cutting forces, tool wear and improving machined surface quality, during laser assisted machining reduction of chip thickness occur and the tendency to creation segmented chip is significantly lower.

Presented research focus on different effects of laser assisted turning of hard-to-cut material (Waspaloy). Selection of proper process parameters which allow to obtain the best tool life and process efficiency is a key element for this paper. On the other hand, analysis of mechanical vibrations during the machining process and characteristics of chip morphology led to define improvement of machining conditions using laser assist.

\section{Experimental}

\subsection{The research stand}

In this paper the wear of round ceramic (6220) cutting inserts of type RPGX 120700 T01020, produced by Sandvik, was investigated. This grade of ceramics is adjusted to machining of superalloys, ex. Waspaloy, thus it was selected for the research. Examination of tool life was carried out on the station for laser assisted machining. This station includes turning centre CTX 310 ecoline coupled with diode laser TRUMP TruDiode 3004 which is integrated with robot Kuka KR 16-2. During the research, material was cooled using carbon dioxide under a pressure of 4 bar.

Next step was the unit for measuring acceleration of mechanical vibrations. The test stand is presented in Figure 1. Measurement of mechanical vibrations' acceleration was carried out using three-axis vibration sensor Brüel \& Kjær of type 4321 which was placed on the lathe's turret. Vibrations were measured in three dimensions, in accordance with Cartesian system of the machine. Measurement of accelerations was executed in three directions: main (compliant with $v_{c}$ vector), feed (compliant with $v_{f}$ vector) and thrust direction. Measurement of wear was carried out with workshop microscope after each machining pass. For evaluation of wear $V B_{c}$ criterion was chosen. This criterion indicates the value of flank face wiping. Moreover, macroscopic and microscopic pictures of chips were presented. 


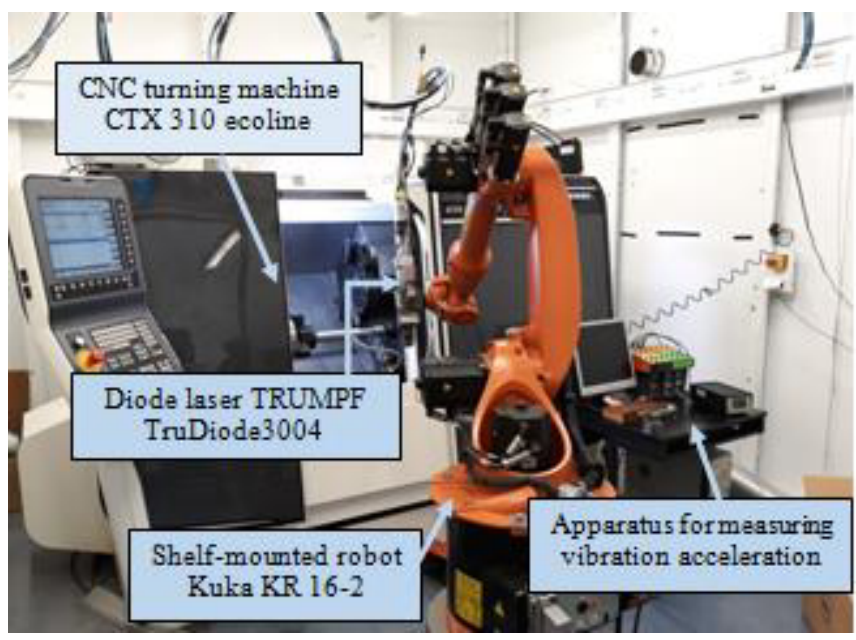

Figure 1. The test stand used for a test.

In order to select proper cutting parameters which enable to obtain the best tool life and process efficiency, machining was carried out with different parameters. Performed tests and various parameters are given in Table 1. Before this test, these cutting parameters were generally applied to conventional machining of Waspaloy.

Table 1. Cutting conditions.

\begin{tabular}{|c|c|c|c|c|}
\hline $\begin{array}{c}\text { Test } \\
\text { number }\end{array}$ & $\begin{array}{c}\text { Cutting speed } \\
\boldsymbol{v} \boldsymbol{c}[\mathbf{m} / \mathbf{m i n}]\end{array}$ & $\begin{array}{c}\text { Cutting depth } \\
\boldsymbol{a}_{\boldsymbol{p}}[\mathbf{m m}]\end{array}$ & $\begin{array}{c}\text { Feed rate } \\
\boldsymbol{f}[\mathbf{m m} / \mathbf{r e v}]\end{array}$ & $\begin{array}{c}\text { Laser beam power } \\
\boldsymbol{P}[\mathbf{W}]\end{array}$ \\
\hline I & 120 & 0,2 & 0,2 & 2000 \\
\hline II & 120 & 0,12 & 0,2 & 1500 \\
\hline III & 150 & 0,12 & 0,2 & 1500 \\
\hline IV & 150 & 0,2 & 0,2 & 2000 \\
\hline V & 150 & 0,2 & 0,2 & 1500 \\
\hline
\end{tabular}

For measurement of mechanical vibrations equipment shown in simplified scheme of circuit in Figure 2 was used. For amplification and processing signal amplifier Brüel \& Kjær NEXUS of type 2692-C was carried out.

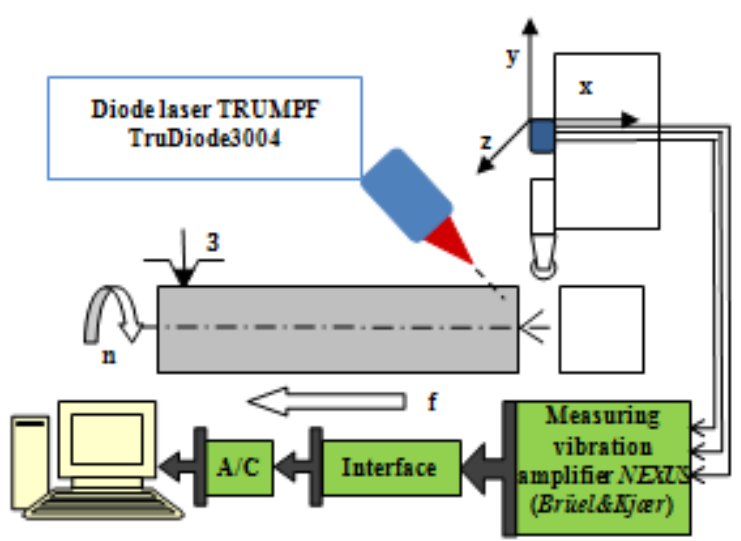

Figure 2. The set-up of experimental apparatus. 


\section{Results and discussion}

\subsection{Analysis of tool wear}

Measurement of tool wear was carried out after each machining pass for all performed tests. By evaluating the wear increase it was possible to define tool life $T$ for particular test and to correlate values of cutting edge wear with microscopic pictures of chips.

Firstly, exemplary progress of $V B_{c}$ wear curve as a function of machining time $t_{s}$ was presented with determined wear criterion $V B_{w}=0,6 \mathrm{~mm}$. Parameters with which the test was performed and the wear of round cutting insert are shown in Figure 3. Flank face wear was also presented in this figure.

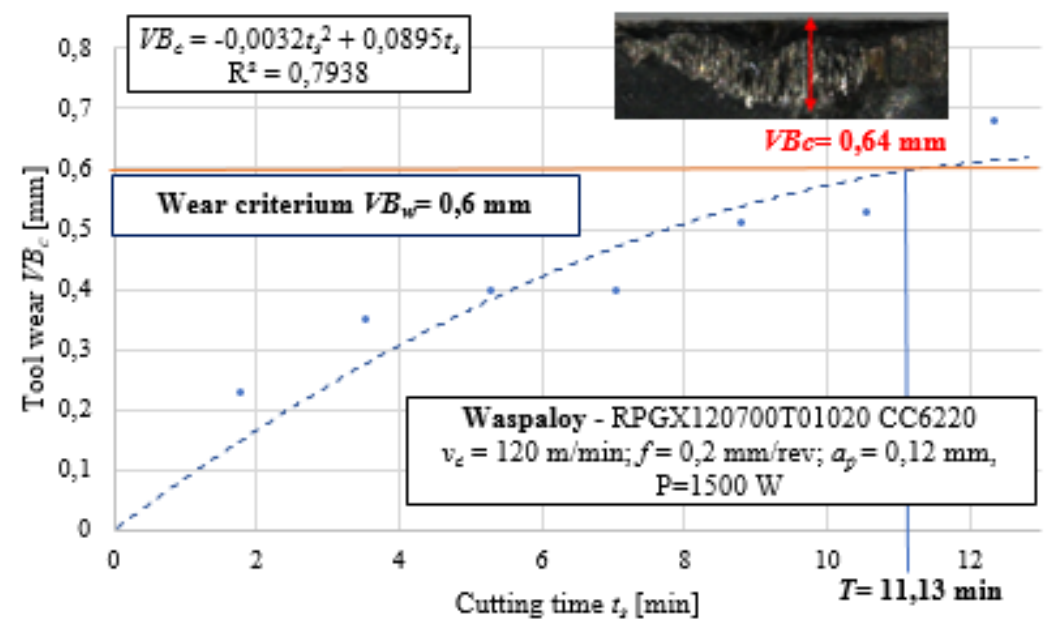

Figure 3. Tool wear in function of time for the investigated ceramic inserts under laser assisted turning.

For parameters $v c=120 \mathrm{~m} / \mathrm{min}, f=0,2 \mathrm{~mm} / \mathrm{rev}, a_{p}=0,12 \mathrm{~mm}, P=1500 \mathrm{~W}$ the best durability of cutting inserts was obtained. On the other hand, by analyzing all the passes, it was spotted that the best efficiency is obtained for lower laser beam power $(1500 \mathrm{~W})$ and lower cutting speed $(120 \mathrm{~m} / \mathrm{min})$.

On the basis of macroscopic observation of chips, the correlation between the value of tool wear and the chip character was spotted. In Figure 4 the character of chip in dependence upon modification of cutting insert wear is presented. At initial stage of wear, ribbon chip occurs and its brown color signifies the low increase in machining temperature. With increasing tool wear, character and color of chip is changing.

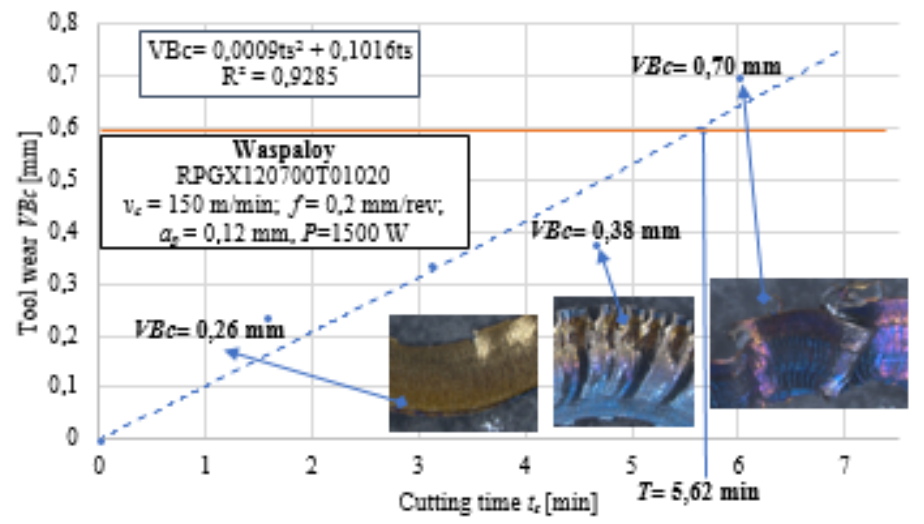

Figure 4. Changes in shape of chip in dependence upon increase of tool wear. 
The occurrence dark blue and purple color signifies the significant increase in machining temperature which is result of higher tool wear. With a wear $V B_{c}=0,38 \mathrm{~mm}$ the significant change in shape of chip is spotted. Segmented chip occurs and due to side flow, at the final stage of wear, it contains anchored particles of machined material.

On the basis of comparative analysis of durability of cutting inserts $T$ and machining process performance $Q$, two combinations of cutting parameters were selected. As the result of applying these parameters the best process performance and tool life were obtained. The evaluation of both criteria is incredibly important to the development of process with the best efficiency. For parameters $v c=150$ $\mathrm{m} / \mathrm{min}, f=0,2 \mathrm{~mm} / \mathrm{rev}, a_{p}=0,5 \mathrm{~mm}, P=1500 \mathrm{~W}$ the best machining efficiency was obtained and using parameters $v c=120 \mathrm{~m} / \mathrm{min}, f=0,2 \mathrm{~mm} / \mathrm{rev}, a_{p}=0,12 \mathrm{~mm}, P=1500 \mathrm{~W}$ the highest ceramic insert durability was obtained. Figure 5 shows comparison of tool life and performance for different cutting parameters.

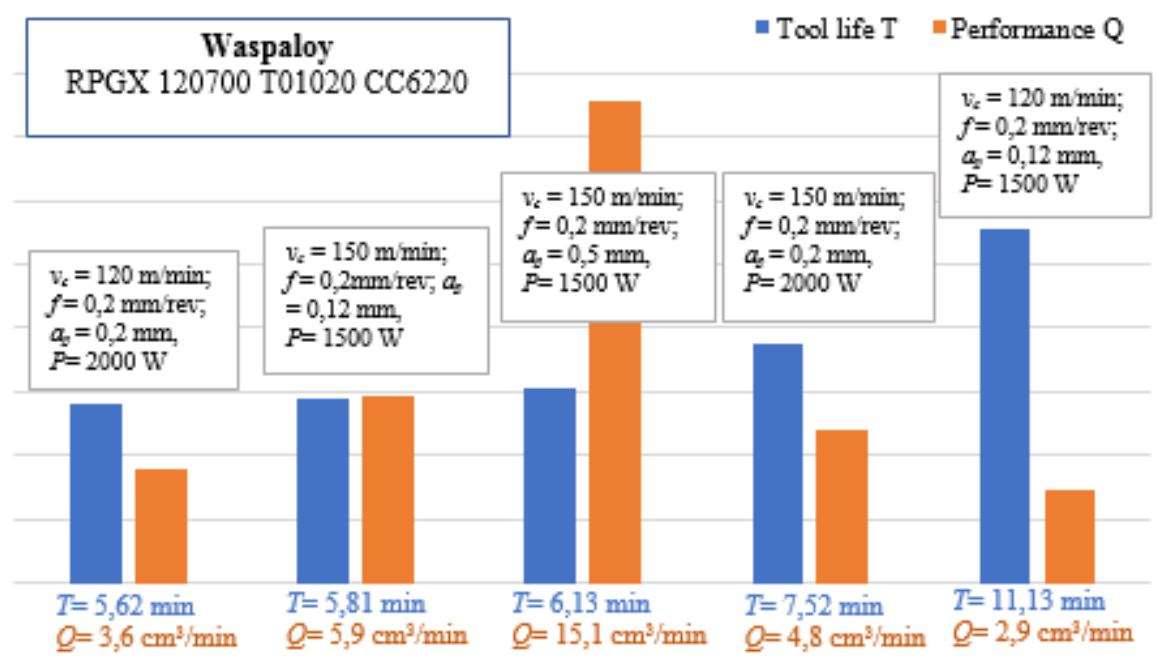

Figure 5. The comparison of process efficiency and durability of cutting inserts for different cutting parameters.

The last step of research was the analysis of vibrations' accelerations which were measured during the process of machining with laser assisted. By analyzing root mean square values $A_{p_{-} R M S}$ of diagnostic measures in three dimensions in accordance with axes of coordinate system, increase in mechanical vibrations with incremental value of flank face wear was spotted. Figure 6 depicts the exemplary chart containing the relation between increment of tool wear and value of root mean square $A_{p_{-} R M S}$
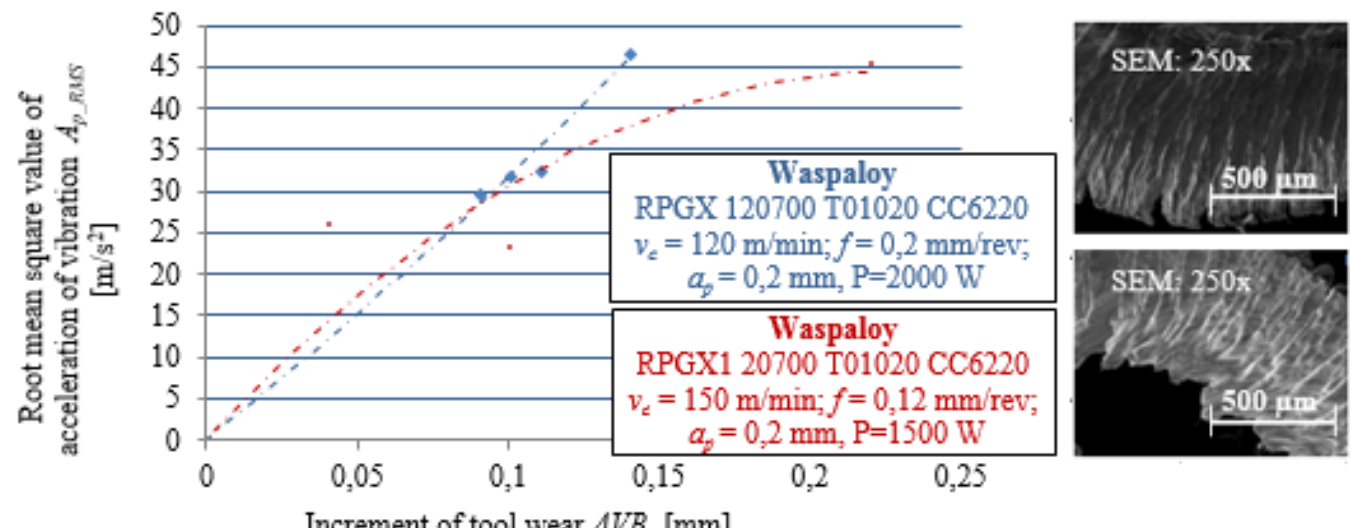

Increment of tool wear $\triangle V B_{c}[\mathrm{~mm}]$

Figure 6. Relations between increment of flank tool wear $\Delta V B_{c}$ and value of acceleration $A_{p_{-}} R M S$. 
The higher increment in tool wear, the larger mechanical vibrations, whereby during the test single drops in vibrations were spotted and they occurred as the result of insignificant increase in tool wear after subsequent machining passes. Built-up edge and reinforcement of Waspaloy could have caused a loss of vibration signals. With increase of vibrations also change in shape of chip occurs and its segmentation is more visible (figure 6).

\section{Conclusions}

On the basis of research following conclusions were formulated:

- Laser assist of turning Waspaloy which is hard-to-cut material, with round ceramics inserts improve material forming and increase durability of cutting inserts, especially if proper cutting parameters are selected $\left(v c=150 \mathrm{~m} / \mathrm{min}, f=0,2 \mathrm{~mm} / \mathrm{rev}, a_{p}=0,5 \mathrm{~mm}, P=1500 \mathrm{~W}\right)$.

- On the basis of chip morphology it can be spotted that shape of chip changes with increasing tool wear and temperature in cutting zone. Chip changes its color and its segmentation occurs. Moreover, anchoring of machined material on cutting edge occurs due to changes in temperature. Built-up edge leads to decrease of vibrations during machining, on the other hand the higher incremental value of flank wear the higher vibration signals.

- Volumetric machining process efficiency and the tool life of ceramics inserts significantly improves if lower laser beam power $(1500 \mathrm{~W})$ is applied. The increase of laser beam power it is not necessary to use, the reinforcement of Waspaloy is more visible and its machinability is not notables.

\section{Acknowledgments}

The presented research results, executed under the domestic project LIDER of No. 164/L6/14/NCBR/2015 with grants for education allocated by the National Centre for Research and Development.

\section{References}

1. P. Hoier, A. Malakizadi, P. Stuppa, S. Cedergren, U. Klement, Wear, Vol.400-401(2018)

2. T. Chwalczuk, S. Legutko, R. Talar, Machine Manufacturing Technology, Vol.29, p.19(2015)

3. Y. Fan, Z. Hao, J. Lin, Z. Yu, Materials and Manufacturing Processes, 01 January 2014

4. S. Olovsjö, L. Nyborg, Wear, Vol.282-283, pp.12-21(2012)

5. D. Przestacki, P. Kieruj, Advances in Manufacturing Science and Technology, Vol.38(4)(2014)

6. D. Przestacki, T. Chwalczuk, MATEC, Vol.136, 02006(2017)

7. R. Polvorosa, A. Suarez, L.N. Lopez de Lacalle, I. Cerrillo, A. Wretland, F. Veiga, Journal of Manufacturing Processes, Vol.26, pp.44-55(2017)

8. S. Wojciechowski, D. Przestacki, T. Chwalczuk, MATEC, Vol.136, 01006(2017)

9. S. Wojciechowski, P. Twardowski, T. Chwalczuk, J.of Phys.: Conference, Vol.483, pp.1-8(2014)

10. Isik, Yahya, Advances in Mechanical Engineering, Vol.8(5)(2016)

11. S. Xavierarockiaraj, P. Kuppan, Procedia Engineering, Vol.97(2014)

12. D. Przestacki, M. Kuklinski, A. Bartkowska, The Inter. J. of Adv. Manuf. Tech., Vol. 93(2017)

13. D. Przestacki, T. Chwalczuk, S. Wojciechowski, The Inter. J. of Adv. Manuf. Tech, Vol.91(9)(2017)

14. Kim, Jong-Do;Lee, Su-Jin ; Suh, Jeong, J. of Mech. Sc. and Tech., Vol.25(4), pp.995-1001(2011)

15. S. Wojciechowski, P. Twardowski, T. Chwalczuk, J. of Phys.: Conf., Vol.483, pp.1-8(2014)

16. P. Kieruj, D. Przestacki, T. Chwalczuk, Mechanik, Vol.8-0/2016

17. M. Rybicki, P. Szablewski, MATEC Web of Conferences, Vol.121, 03020(2017)

18. Y. Xiong, W. Wang, R. Jiang, K. Lin, M. Shao, Materials, Vol.11(4)(2018)

19. K. Venkatesan, R. Ramanujam, P. Kuppan, Int J Adv ManufTechnol, Vol.91:3807-3821(2017) 